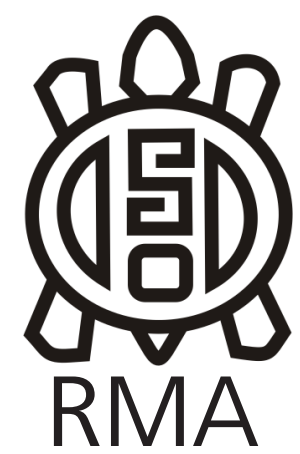

Arqueología

\title{
Cronología y procesos de formación en niveles de ocupación prehispánicos de selvas occidentales meridionales (Horco Molle, Tucumán)
}

\author{
Chronology and formation processes in prehispanic of occupational \\ levels in selvas occidentales meridionales (Horco Molle, Tucumán)
Mario Gabriel Maldonado*, Sergio Fabian Cano* y María Marta Sampietro Vattuone ${ }^{* * *}$

\begin{abstract}
"CONICET. Laboratorio de Geoarqueología, Facultad de Ciencias Naturales e Instituto Miguel Lillo, Universidad Nacional de Tucumán, Argentina. E-mail: gabrielmaldonado23@yahoo.com.ar; ${ }^{* *}$ Laboratorio de Geoarqueología, Facultad de Ciencias Naturales e Instituto Miguel Lillo, Universidad Nacional de Tucumán, Argentina. E-mail: scano2171@gmail.com; ${ }^{* *}$ CONICET. Laboratorio de Geoarqueología, Facultad de Ciencias Naturales e Instituto Miguel Lillo, Universidad Nacional de Tucumán, Argentina. E-mail: sampietro@tucbbs.com.ar
\end{abstract}

\begin{abstract}
Resumen
Se analizaron procesos de formación y cronología de niveles de ocupación de Horco Molle (Tucumán), localidad emplazada en la parte $S$ de las Selvas Occidentales del Noroeste Argentino. Para ello se efectuaron sondeos y excavaciones, descripciones estratigráficas, determinaciones de $\mathrm{pH}$, registro de trazas de alteración en conjuntos cerámicos, clasificaciones tipológicas y un fechado radiocarbónico. Los niveles de ocupación, ubicados en el sector distal de un abanico aluvial, se apoyan sobre un paleosuelo, cubiertos por depósitos aluviales sobre los que se formó el suelo actual o por grava. La acidez variable de los suelos (entre 5,38 y 6,47) explican en parte la casi ausencia de materiales arqueológicos orgánicos. El desplome de una estructura arquitectónica de barro sobre una superficie de ocupación preservó un contexto con desechos de facto. El pisoteo intervino en la fractura de tiestos de los contextos analizados. La variedad de tipos cerámicos presentes en las ocupaciones se corresponde con la que caracteriza a las fases Chuscha (200-400 DC) y Choromoro (400-700 DC), estimación cronológica que coincide con un fechado de $1639 \pm 57$ AP. Los resultados obtenidos destacan la adecuación de la perspectiva geoarqueológica para el hallazgo e investigación de niveles de ocupación prehispánicos en ámbitos selváticos.
\end{abstract}

Palabras claves: Niveles de ocupación arqueológicos; Sociedades agropastoriles; Selvas Occidentales meridionales; Geoarqueología; Procesos de formación de sitios

\begin{abstract}
Formation processes and chronology of archaeological occupations of Horco Molle (Tucuman) were analyzed, this area is located in the south part of Northwestern Argentina. Pits and excavations, stratigraphic descriptions, $\mathrm{pH}$ measurements, trace of alteration analyses in ceramic assemblages, typological classifications, and a radiocarbon dating were made. Levels of occupation were located in the distal part of an alluvial fan, lying over a paleosoil, covered by alluvial deposits (with recent soil development) or gravels. The variable acidity of the soil (among 5,38 $y 6,47)$ explains in part the near absence of organic archaeological materials. The collapse of an architectural structure made of mud above a surface of occupation preserved an archaeological context with de facto refuses. The trampling intervened in the fracture of pottery sherds belonging to the analyzed contexts. The variety of ceramic types present in the occupations is comparable to which characterizes the Chuscha (200-400 AD) and Choromoro (400-700 AD) phases, in coincidence with a dating of $1639 \pm 57 \mathrm{BP}$. The results obtained highlight the adequacy of geoarchaeological perspective for the discovery and research of occupational surfaces in forested areas.
\end{abstract}

Keywords: Archaeological occupational levels; Agropastoral societies; Selvas Occidentales meridionales; Geoarcheology; Site formation processes

La arqueología de Selvas Occidentales (González 1977) del Noroeste Argentino (NOA) es menos conocida que la de los valles de altura vecinos. Ello responde, entre otros factores, a la escasa visibilidad y preservación arqueológica dada la densidad de la vegetación, la acción de procesos de erosión y sedimentación y al impacto del laboreo de tierras, dificultando la detección de sitios, la elección de los lugares a excavar y el hallazgo de contextos poco alterados con los consiguientes problemas para efectuar inferencias. 
Dentro del espacio aludido efectuamos investigaciones en la localidad de Horco Molle (Cano 2002; Maldonado et al. 2009, 2010a, 2010b, 2011 entre otros) ubicada en el piedemonte oriental de la sierra de San Javier (Dpto. Yerba Buena, Tucumán) a 13 km de San Miguel de Tucumán, arqueológicamente asimilable a lo que se ha denominado "cultura Candelaria" (Heredia 1975; Ryden 1936; entre otros). Allí, la visibilidad arqueológica es muy baja por la cobertura sedimentaria y vegetal, y las evidencias de superficie son casi exclusivamente tiestos y líticos. Los lugares de hallazgos más significativos son las cumbres de las Lomas de Imbaud, el campo de cultivo de la Escuela de Agricultura y Sacarotécnia y sus lindes, así como los lugares denominados Anta Yacu y El Funicular (Maldonado et al. 2011; Miguez y Caria 2010) (Figura 1).

Desde una perspectiva geoarqueológica de procesos de formación de sitios (Rapp y Hill 1998; Schiffer 1996), se investigaron los procesos naturales de formación, apuntando al hallazgo de contextos arqueológicos preservados en condiciones de baja visibilidad y a su caracterización cronológica y cultural. En esta oportunidad, el objetivo es presentar el análisis detallado de contextos en los que se identificaron niveles de ocupación e indicadores cronológicos relativos, junto con un fechado radiocarbónico.

\section{Antecedentes}

Dentro de la problemática de los procesos de formación de sitios, el primer antecedente de investigación para Horco Molle fue desarrollado por uno de nosotros (Cano 2002), evaluando los procesos de alteración naturales y culturales posdepositacionales que actuaron y actúan sobre el área, mediante el análisis de alteraciones formales

Figura 1. Área de estudio (sombreada).

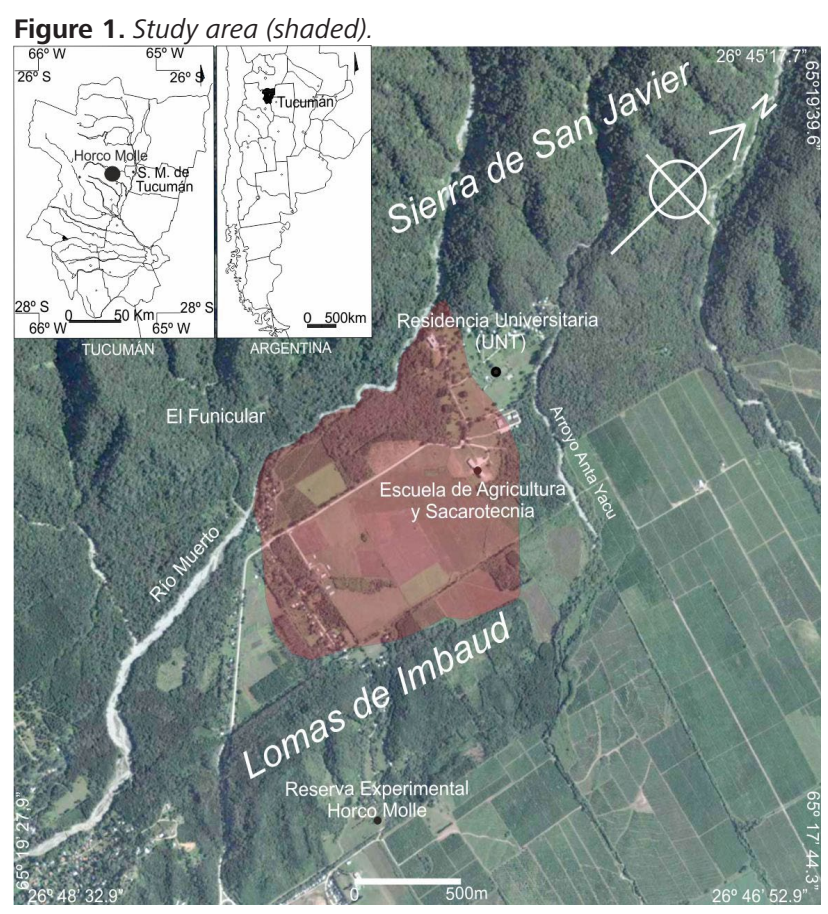

en los fragmentos cerámicos de excavación junto con aspectos geoambientales, biológicos, antrópicos y climáticos. Se estableció que: los procesos fluviales y aluviales provocaron la alteración formal, movilización y sedimentación de materiales arqueológicos de superficie; existe muy baja probabilidad de conservación de evidencias arqueológicas orgánicas bajo el clima subtropical, procesos de erosión marcados y suelos relativamente ácidos; el arado de la tierra y el empleo de maquinaria para la construcción de pequeños diques provocó remoción y rotura mecánica de los materiales culturales.

Posteriormente, Míguez y Cano (2006) analizaron la incidencia de los cambios medioambientales sobre el registro arqueológico en un período reciente (1976-2005). Destacaron la erosión hídrica acelerada por la tala y el cultivo que produjeron arrastre de materiales culturales y fragmentación, la incidencia de raíces de árboles y pisoteo de animales en la fragmentación cerámica y las alteraciones microespaciales, la acidez de los suelos y actividad microbiológica en la ausencia de restos arqueológicos orgánicos, y los procesos de disturbación derivados del crecimiento suburbano.

Además, se realizaron investigaciones geoarqueológicas en la zona (Maldonado et al. 2009, 2010a, 2010b, 2011, entre otros). A partir del análisis geomorfológico, estratigráfico, de trazas de alteración en fragmentos cerámicos e indicadores cronológicos relativos, se estableció la formación arqueológica general de Horco Molle desde los inicios de la ocupación prehispánica hasta la actualidad, identificando sectores con mayor o menor potencial para el hallazgo de contextos arqueológicos relativamente preservados.

Hasta el presente, en Horco Molle se registraron y describieron de forma general algunos niveles de ocupación con un cierto grado de preservación (Maldonado et al. 2009: 317-320, 2011: 118-119; Míguez 2005: 61-63; Miguez y Cuenya 2009), pero no se analizaron en detalle los procesos que intervinieron en la formación de dichos contextos, sus cronologías relativas, ni se efectuaron dataciones absolutas. Sin embargo, se obtuvieron fechados de contextos funerarios hallados aisladamente (Míguez y Caria 2016). Este problema es general para la arqueología del sector meridional de Selvas Occidentales: son escasos los niveles de ocupación investigados, caracterizados someramente y casi nunca poseen dataciones absolutas (salvo Caria y Sayago 2008: 16 y 18; Heredia 1975: 106). Contrariamente, la mayoría de los fechados corresponden a contextos de entierros humanos aislados (Berberián et al. 1977; Fasth 2003; Heredia 1971; Muñoz 2002).

\section{Metodología}

Se efectuaron sondeos y excavaciones profundizados 
en niveles artificiales de $10 \mathrm{~cm}$. Se distribuyeron longitudinalmente a la pendiente general de un abanico aluvial, con el criterio de abordar las diferencias internas que suelen presentan estas geoformas: zonas proximal y media con pendientes más pronunciadas donde predomina la erosión, y sector distal con declive más suave donde domina la sedimentación (Bloom 1998), con variaciones estratigráficas entre dichas zonas y posibilidades de una mayor preservación arqueológica en los sectores de acumulación (Schiffer 1996). Debido a la nula visibilidad de arquitectura, la ubicación precisa de cada sondeo tuvo en cuenta la presencia de artefactos en superficie, en cortes verticales del terreno y zonas de hallazgos previos.

Como resultado, en tres lugares ${ }^{1}$ se hallaron niveles de ocupación aparentes (lugares 3, 7 y 8) y también una secuencia estratigráfica con materiales arqueológicos acumulados naturalmente a primera vista (lugar 4) (Figura 2). Se describieron los rasgos macromorfológicos de los perfiles estratigráficos en el campo y se determinó el pH (acidez real o actual) en laboratorio.

Se recuperaron 2889 artefactos (2801 fragmentos cerámicos y 88 líticos), para los cuales se registraron las siguientes variables o atributos: 1-cantidad de artefactos; 2-distribución vertical; 3-diversidad (lítico, cerámica, material cultural actual, otros); 4-inventario (conteo por tipo de material); 5-reensamblaje de tiestos; 6-medida de desorganización (número de fragmentos cerámicos/ Número Mínimo de Vasijas); 7-partes representadas en los fragmentos (borde, cuello, asa, base y otros); 8-tamaño de los tiestos (<1 cm; 1,1-3 cm; 3,1-6 cm; 6,1-9 cm; > $9 \mathrm{~cm}$ ); 9-forma de los fragmentos (bien redondeados/ redondeados, subredondeados/subangulosos, angulosos/ muy angulosos); 10-redondeo de bordes de los tiestos (redondeados, no redondeados (Maldonado et al. 2010b; Schiffer 1996).

Los fragmentos cerámicos se clasificaron en grupos macroscópicos (PRIMERA CONVENCIÓN DE ANTROPOLOGÍA 1966) distinguiendo entre los decorados por técnicas decorativas y entre los no decorados por acabado de superficie. La elección de estos criterios permitió establecer comparaciones con la tipología de Heredia (1975) y reconocer la presencia de algunos tipos cronológicamente diagnósticos ${ }^{2}$. El material lítico fue

\footnotetext{
${ }^{1}$ Ante las dificultades de establecer límites acordes con la noción de sitio arqueológico, se emplea el concepto de lugares o loci que incluyen a los hallazgos aislados de superficie y a los asentamientos (Schlanger 1992). Los lugares arqueológicos son espacios de características adecuadas para una determinada función o combinación de funciones (Binford 1982). Los lugares arqueológicos pueden incluirse en localidades arqueológicas, una unidad espacial mayor que conserva la posible unidad de interacción entre ellos (Nastri 1997-1998: 251).

${ }^{2}$ En dicho trabajo, el principal criterio de diferenciación entre la cerámica no decorada es la variedad de acabados de superficie y el tamaño de las inclusiones (Heredia 1975: 74), este último no se emplea aquí. En la alfarería decorada el principal criterio, y a veces el único, es el de las técnicas decorativas (Heredia 1975: 76).
}

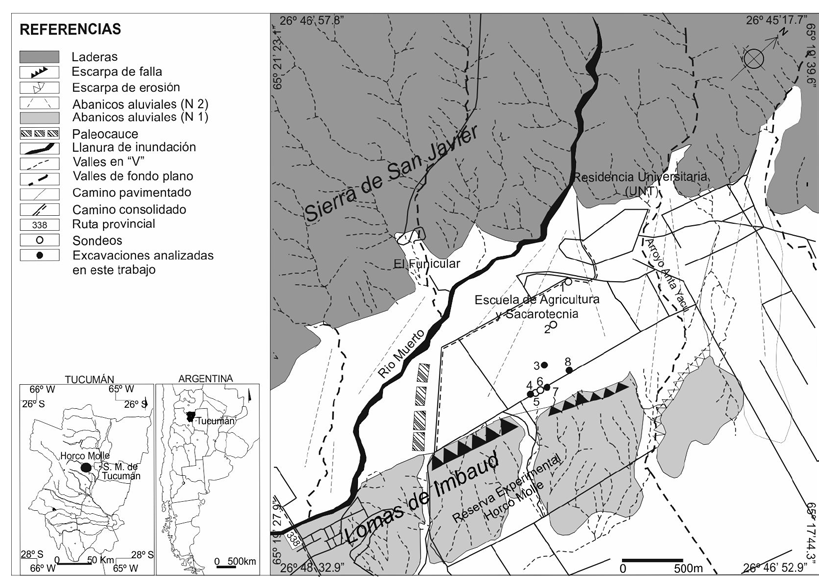

Figura 2. Mapa geomorfológico y ubicación de los sondeos efectuados (tomado de Maldonado et al. 2009 con modificaciones).

Figure 2. Geomorphologic map and places of pits made (taken from Maldonado et al. 2009 with changes).

clasificado según la propuesta de Aschero (1975, 1983), distinguiéndose variedades generales de materias primas, separando entre: desechos de talla, núcleos, artefactos formatizados y con rastros complementarios.

El análisis descripto fue aplicado al registro arqueológico de cada nivel artificial excavado. Los datos se analizaron para cada secuencia estratigráfica comparando y asociando los resultados obtenidos para las variables, permitiendo determinar los procesos de formación y su secuencia temporal. Una muestra de carbón vegetal fue datada por AMS en el Accelerator Mass Spectrometer Laboratory (Universidad de Arizona) y la fecha obtenida fue calibrada a 68,2 \% y 95,4\% de probabilidad con la curva SHCal 13 utilizando el programa OxCal v. 4.2. De la misma manera se calibraron dos fechados publicados y se elaboró una secuencia con las dataciones de la localidad.

\section{Resultados}

En el lugar 3 se excavaron dos cuadrículas contiguas de $1 \mathrm{x}$ $1 \mathrm{~m}$ de lado en niveles artificiales de $10 \mathrm{~cm}$, hasta los 0,80 $m$ de profundidad. La estratigrafía presentó horizontes $\mathrm{A} / \mathrm{C} / 2 \mathrm{C} / 3 \mathrm{~B} / 3 \mathrm{BC}$, correspondiendo los horizontes $\mathrm{A} / \mathrm{C}$ al suelo actual, el horizonte $2 \mathrm{C}$ a sedimentos de origen antrópico (lo cual se explicará más adelante) y los horizontes $3 \mathrm{~B} / 3 \mathrm{BC}$ a un paleosuelo enterrado. Estos dos últimos horizontes presentan cutanes, continuos y discontinuos respectivamente. Los valores de $\mathrm{pH}$ son débilmente ácidos, alcanzando la neutralidad en el horizonte más profundo (Figura 3).

Se recuperaron 468 tiestos, 23 líticos y fragmentos de carbón distribuidos por encima del paleosuelo, así como material cultural moderno en los primeros $20 \mathrm{~cm}$ del suelo actual. Estratigráficamente, las mayores frecuencias de hallazgos corresponden a los horizontes C y $2 \mathrm{C}$. La alteración de los conjuntos cerámicos es mayor en sentido estratigráfico ascendente, aumentando en esa dirección 
la proporción de fragmentos $<3 \mathrm{~cm}$, de formas muy redondeado/redondeado y de bordes redondeados. La menor alteración corresponde a los conjuntos cerámicos del horizonte $2 \mathrm{C}$ (nivel 4), con tiestos de tamaño $>9 \mathrm{~cm}$, predominio de fragmentos angulosos/muy angulosos y de bordes no redondeados, medida de desorganización ligeramente superior y mayor variedad de partes cerámicas representadas. Se infiere que la secuencia fue formada por acumulación progresiva de materiales arqueológicos y sedimentos arrastrados por escorrentía natural (Figura 3).

Tipológicamente, a través de la secuencia estratigráfica dominan ampliamente los tiestos no decorados, principalmente Candelaria alisado y en frecuencias menores y estratigráficamente discontinuos fragmentos Toscos, Candelaria pulido, Engobados y Ante alisado. Entre los decorados, están representados también de forma discontinua los grupos o tipos Gris inciso, Marrón inciso, Candelaria acanalado, Candelaria gris grabado, Modelado y Candelaria rojo pintado. Las mayores variedades de tipos y grupos cerámicos corresponden a los niveles con mayor frecuencia de fragmentos. En el nivel 4 los grupos y tipos registrados se asocian a un fechado radiocarbónico de $1639 \pm 57$ (AA104699) (Figura 3, Tabla 1).

Para analizar detalladamente el registro arqueológico más profundo y mejor preservado, debe distinguirse estratigráficamente entre una superficie de ocupación sobre el paleosuelo y el horizonte $2 \mathrm{C}$ (Figuras 4).
En la superficie de ocupación se identificó un sector ligeramente endurecido sobre el cual se encontraron grandes fragmentos cerámicos, fracturados in situ, correspondientes a partes de una vasija Candelaria acanalado. Además se hallaron tiestos de una vasija del grupo Modelado y de otras, trozos de carbón vegetal dispersos, fragmentos pequeños de huesos carbonizados y terrones de sedimento alterados térmicamente (rubefacción), asociación que señala un locus de actividad humana con el fechado de $1639 \pm 57$ AP (AA104699) (Figura 4).

Por encima, en el horizonte $2 \mathrm{C}$, se registraron en planta dos trazas oscuras elongadas atravesando paralelamente casi toda la cuadrícula 3 (1), interpretadas como la humificación de maderas (Figura 4) en un fenómeno similar al de los llamados postmold (Schiffer 1996). Estas trazas, junto con las notables diferencias del horizonte 2C (más claro y compacto que los restantes), permiten proponer que son los restos de una estructura en barro y madera colapsada sobre el piso habitacional, que aplastó y enterró los materiales culturales que se hallaban sobre él, tales como la vasija Candelaria acanalado y del molino de arenisca.

En el horizonte $2 \mathrm{C}$ se evidenció dispersión general de materiales arqueológicos y los trozos de un molino en arenisca. Previamente, parte de ese material cultural estuvo depositado en la superficie de ocupación y luego fue levemente desplazado al horizonte $2 \mathrm{C}$ antes de la estabilización postdepositacional, tal como lo

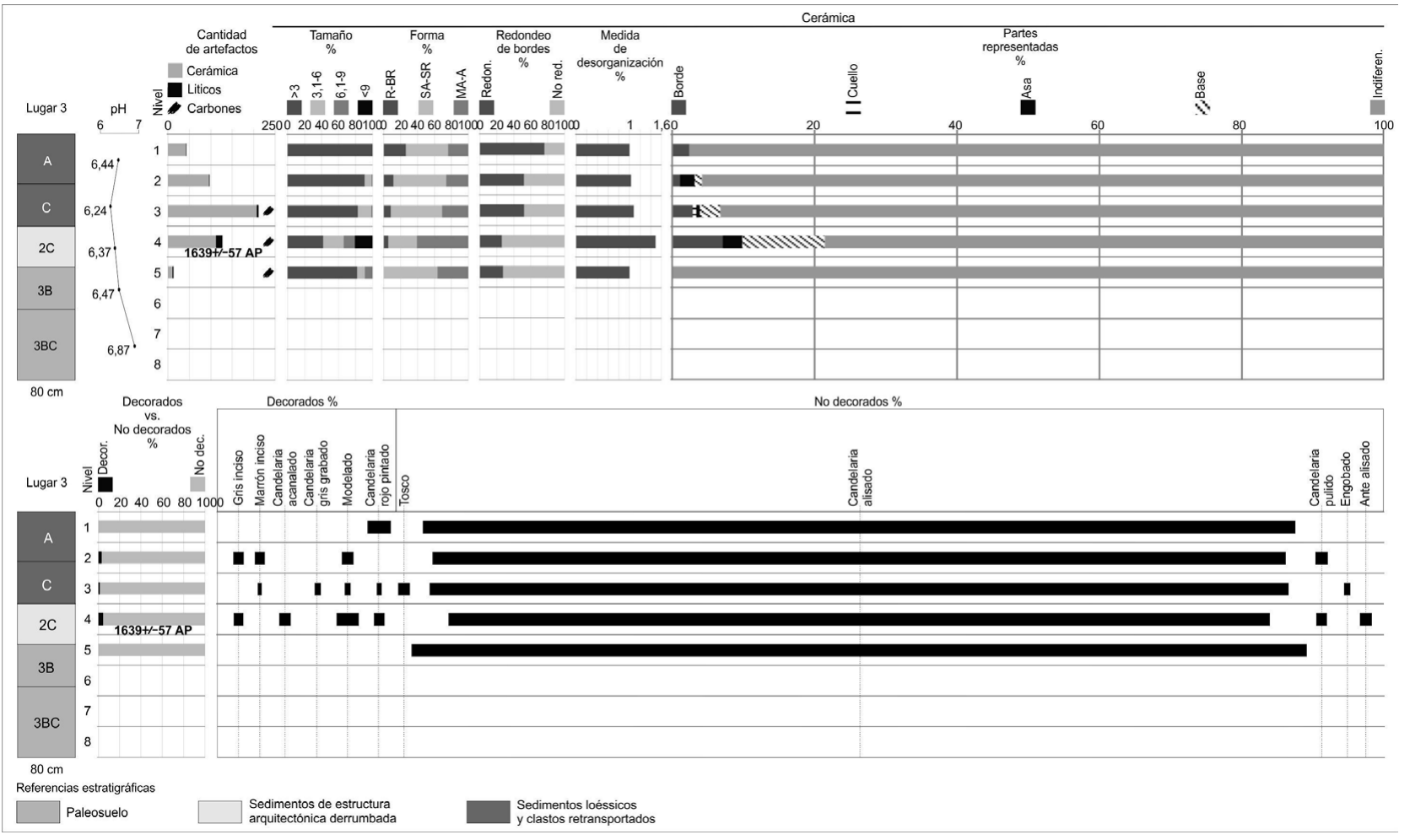

Figura 3. Variaciones estratigráficas de trazas de alteración, grupos y tipos cerámicos del Lugar 3.

Figure 3. Stratigraphic variations of traces of alteration, ceramic groups and types from Place 3. 
Tabla 1. Fechado radiocarbónico obtenido para el Lugar 3.

Table 1. Radiocarbon date obtained for the Place 3.

\begin{tabular}{|c|c|c|c|c|c|}
\hline \multicolumn{6}{|c|}{ Lugar 3} \\
\hline $\begin{array}{l}\text { Cod. } \\
\text { Lab. }\end{array}$ & Procedencia & $\begin{array}{l}\text { Fechado } \\
\text { C14 }\end{array}$ & $\begin{array}{c}\text { Edad calibrada } \\
1 \text { sigma } \\
68,2 \%\end{array}$ & $\begin{array}{c}\text { Edad calibrada } \\
2 \text { sigma } \\
95,4 \%\end{array}$ & $\begin{array}{l}\text { Material } \\
\text { fechado }\end{array}$ \\
\hline AA104699 & $\begin{array}{l}\text { Horco Molle- } \\
\text { Sondeo } 3(2) \text {, } \\
\text { nivel } 4\end{array}$ & $1639 \pm 57 \mathrm{AP}$ & $\begin{array}{c}419-543 \\
\text { DC }\end{array}$ & $\begin{array}{c}342-609 \\
\text { DC }\end{array}$ & $\begin{array}{l}\text { Carbón } \\
\text { vegetal }\end{array}$ \\
\hline
\end{tabular}

indican las evidencias presentes en ambas unidades estratigráficas (fragmentos de una vasija Candelaria alisado, los de otra del grupo Modelado y los del molino) (Figura 4). Sin embargo, otros procesos pudieron introducir evidencias. La estructura en barro pudo contener materiales arqueológicos de otros contextos incluidos accidentalmente en la masa, los que luego del derrumbe pudieron quedar en el horizonte $2 \mathrm{C}$. También el escurrimiento superficial pudo introducir materiales ajenos al contexto antes de la estabilización. Aunque es difícil identificar con total seguridad los materiales introducidos por estos procesos cabría esperar que, entre los fragmentos cerámicos, los de procedencia externa sean los de menor tamaño, de formas muy redondeado/ redondeado y de bordes redondeados, fácilmente introducidos de forma no intencional en el barro para la construcción y con evidencias de desplazamiento previo por escorrentía hídrica.

Complementariamente, los patrones de tamaño de fragmentos del horizonte $2 \mathrm{C}$ y de la superficie de ocupación evidencian que predominan los $<3 \mathrm{~cm}$, compatible con los resultados de procesos de pisoteo (Nielsen 1991), coexistentes con fragmentos de categorías de mayor tamaño sin pisotear.

Por otro lado, en el lugar 7 se excavaron cinco cuadriculas de $1,50 \times 1,50 \mathrm{~m}$ en niveles artificiales de $10 \mathrm{~cm}$, en torno al hallazgo de una urna funeraria. Allí la secuencia estratigráfica, de 0,80 m de profundidad, evidenció en la parte superior la presencia de una capa de grava enterrando un paleosuelo formado por horizontes $2 \mathrm{~A} / 2 \mathrm{~B} / 2 \mathrm{C}$. El horizonte $2 \mathrm{~B}$ presenta cutanes continuos que recubren paredes y poros. Los valores de $\mathrm{pH}$ son débilmente ácidos, acercándose a la neutralidad con la profundidad (Figura 5).

Se recuperaron 587 fragmentos de cerámica, 21 líticos y se registraron espículas de carbón, distribuidos estratigráficamente entre la capa de grava y el horizonte 2A, así como material cultural actual en la capa superficial. La alteración de los conjuntos cerámicos es ligeramente mayor en la capa de grava, con las mayores proporciones de tiestos $<3 \mathrm{~cm}$ y de 3,1-6 cm, de forma bien redondeados/redondeados y con bordes redondeados. Los fragmentos menos alterados corresponden al horizonte $2 \mathrm{~A}$ del paleosuelo, donde se halla la mayor cantidad de artefactos (Figura 5).

Tipológicamente los tiestos más frecuentes no tienen decoración, en su mayor parte son Candelaria alisado

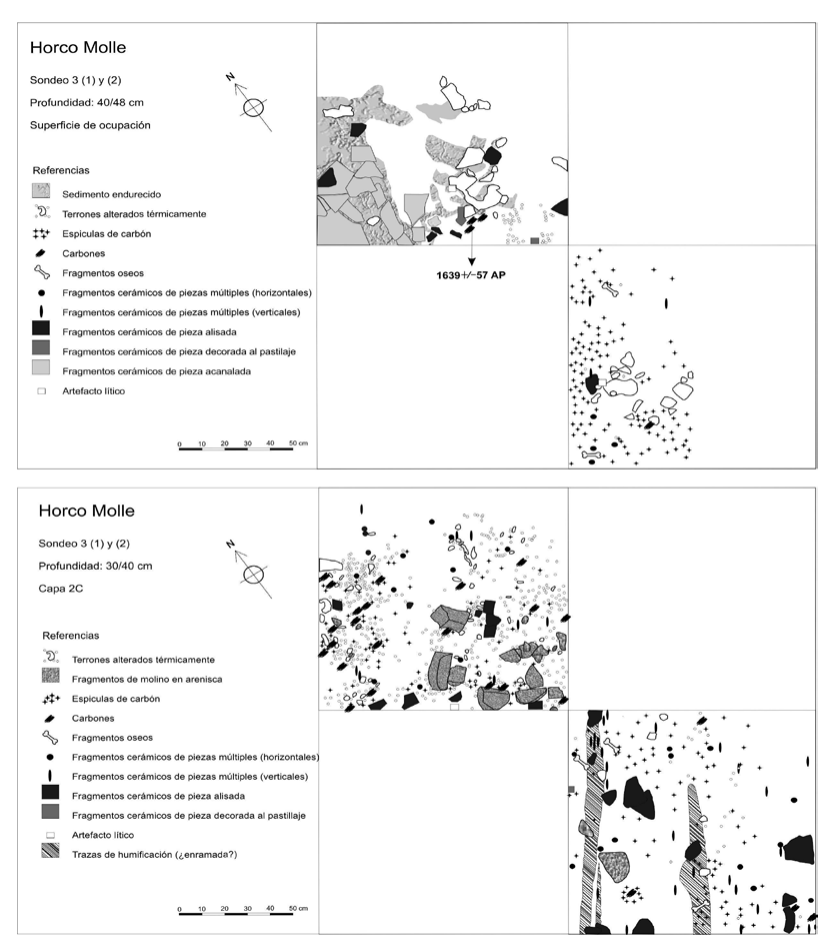

Figura 4. Lugar 3, superficie de ocupación (arriba) y relleno superpuesto a la superficie de ocupación (abajo) (tomado de Maldonado et al. 2009 con modificaciones).

Figure 4. Place 3, occupational surface (up) and fill superimposed on the occupational surface (down) (taken from Maldonado et al. 2009 with changes).

y en muy bajas frecuencias de los grupos o tipos Tosco, Candelaria pulido y Ante alisado. Entre los decorados están presentes los tipos Candelaria gris inciso, Candelaria rojo pintado y Chuscha rojo/crema. La mayor diversidad tipológica corresponde al nivel 2, con tiestos de todos los tipos y grupos mencionados (Figura 5).

La distribución horizontal de hallazgos en la capa de grava muestra una dispersión generalizada. En el horizonte 2A, en tanto, se identificó una lente de arcilla asociada a una concentración de artefactos (cuadrícula $\mathrm{H} 2 \mathrm{e} \mathrm{I2)} \mathrm{donde} \mathrm{se} \mathrm{recuperaron,} \mathrm{entre} \mathrm{otros} \mathrm{hallazgos,} 3$ fragmentos cerámicos indiferenciados de 13 a $15 \mathrm{~cm}$ y un asa en correa que pertenecerían a una misma vasija Candelaria alisado, 2 puntas de proyectil apedunculadas, un núcleo y cuatro lascas, todos en cuarzo. En el horizonte 2B del paleosuelo se halló una urna funeraria con tapa de laja metamórfica que contenía restos óseos de tres infantes, tres cuentas líticas (en anfíbol, roca volcánica (i?) y crisocola) y una vasija zooantropomorfa Candelaria modelado (Colaneri et al. 2003; Ruiz 2003), y se obtuvo un fechado radiocarbónico de $1420 \pm 20$ AP (UGA22275) 


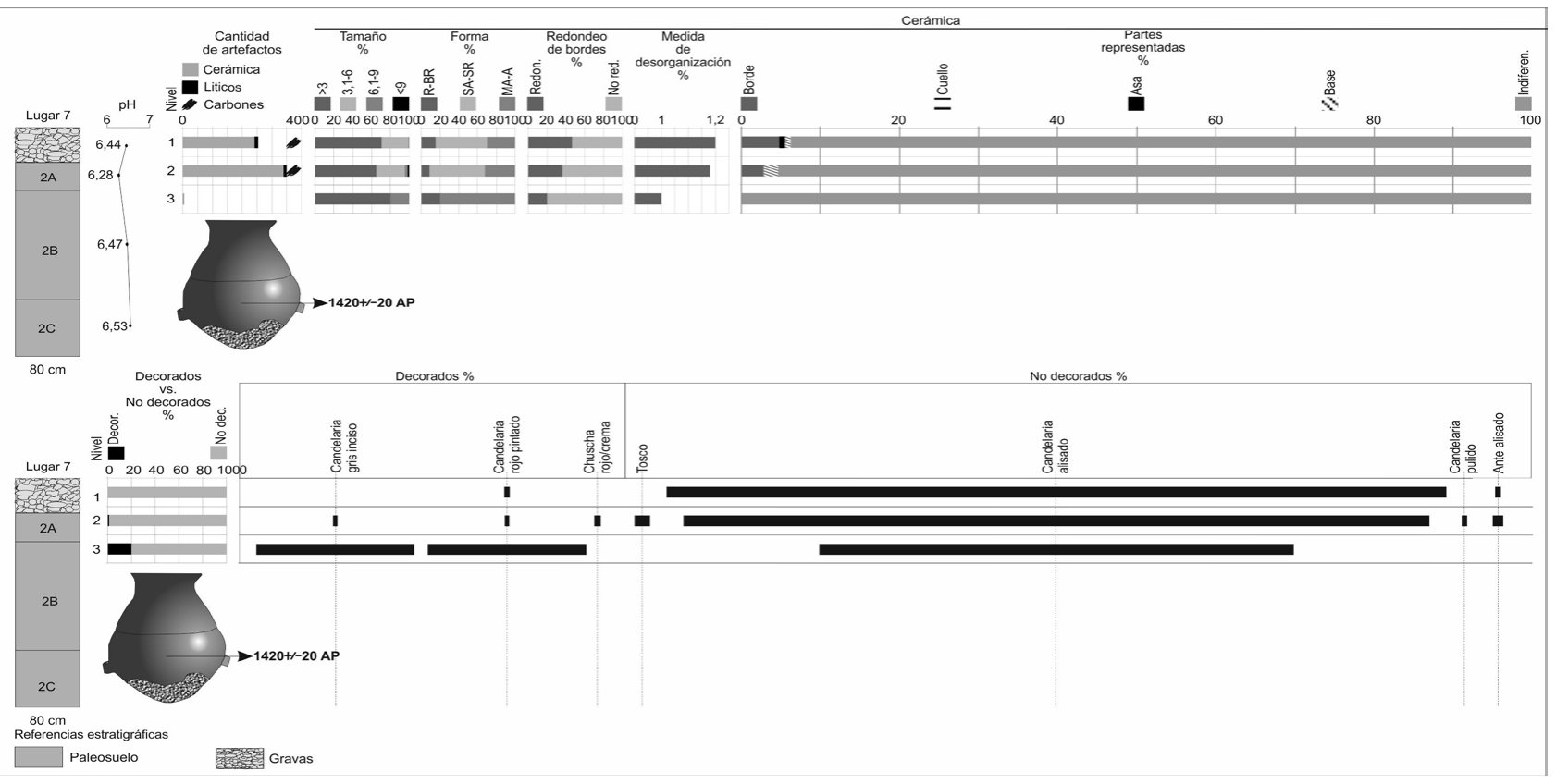

Figura 5. Variaciones estratigráficas de trazas de alteración, grupos y tipos cerámicos del Lugar 7.

Figure 5. Stratigraphic variations of traces of alteration, ceramic groups and types from Place 7.

a partir del colágeno de un fémur (Míguez y Caria 2016: 2022) (Figura 6). Debido a que los depósitos sedimentarios suprayacentes a la urna fueron erosionados por una cárcava incipiente, la evidencia estratigráfica no permite establecer la relación temporal de este hallazgo con el nivel de ocupación. Sin embargo, como se discutirá más adelante, la datación es congruente con las características estilísticas de la cerámica del contexto

Considerando la mayor frecuencia, variabilidad artefactual y la asociación de las evidencias documentadas en los horizontes $2 \mathrm{~A}$ y $2 \mathrm{~B}$, se puede proponer que la misma es de origen cultural. Pero la ausencia de reensamblaje de fragmentos revela que se trata de desechos secundarios, afectados por escorrentía superficial pero en menor grado que los hallazgos de la capa de grava.

En el lugar 8 se excavó una trinchera de $2 \times 1 \mathrm{~m}$ de lado en niveles artificiales de $20 \mathrm{~cm}$. La excavación alcanzó 1,20 m de profundidad. El perfil estratigráfico se compone del suelo actual formado por los horizontes $A p / B$, superpuesto a un paleosuelo representado por un horizonte $2 \mathrm{Bt}$. Los valores de $\mathrm{pH}$ van desde medianamente ácido en el horizonte más superficial hasta neutro en el más profundo (Figura 7).

Se recuperaron 338 fragmentos cerámicos, 15 líticos y se registraron espículas de carbón, distribuidos por encima del paleosuelo y más frecuentes en el nivel 3. La

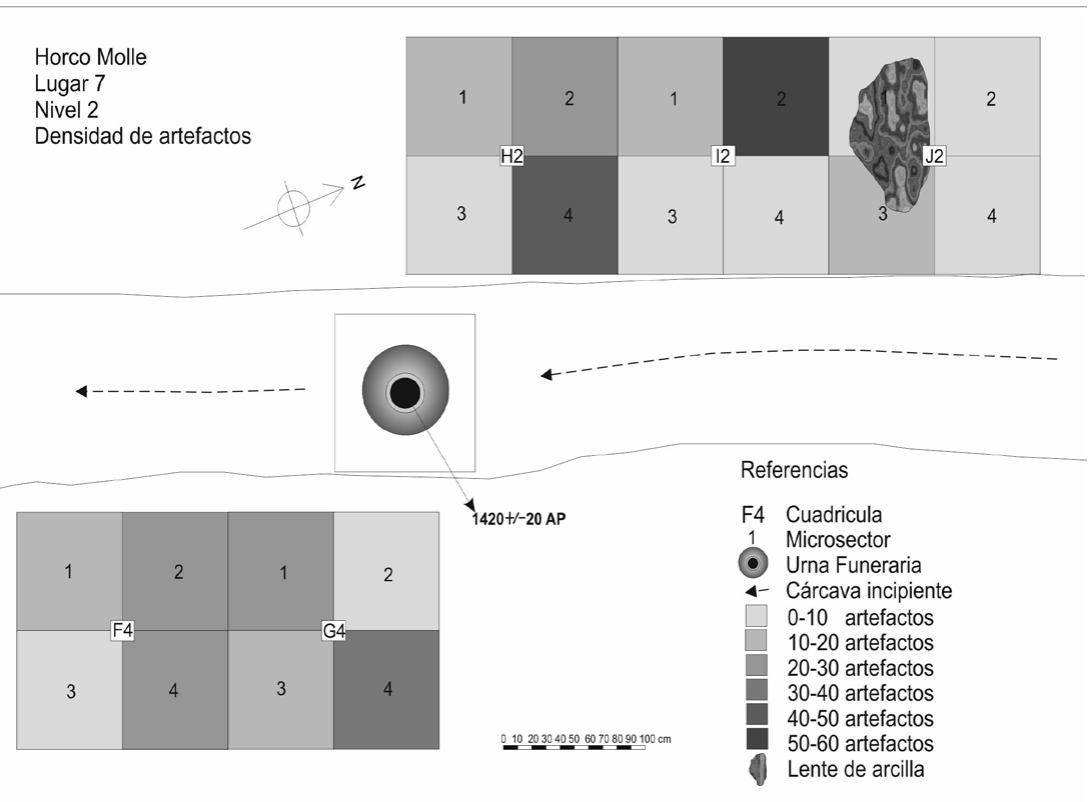

Figura 6. Lugar 7, densidad de hallazgos (tomado de Maldonado et al. 2009 con modificaciones).

Figure 6. Place 7, density of findings (taken from Maldonado et al. 2009 with changes). 


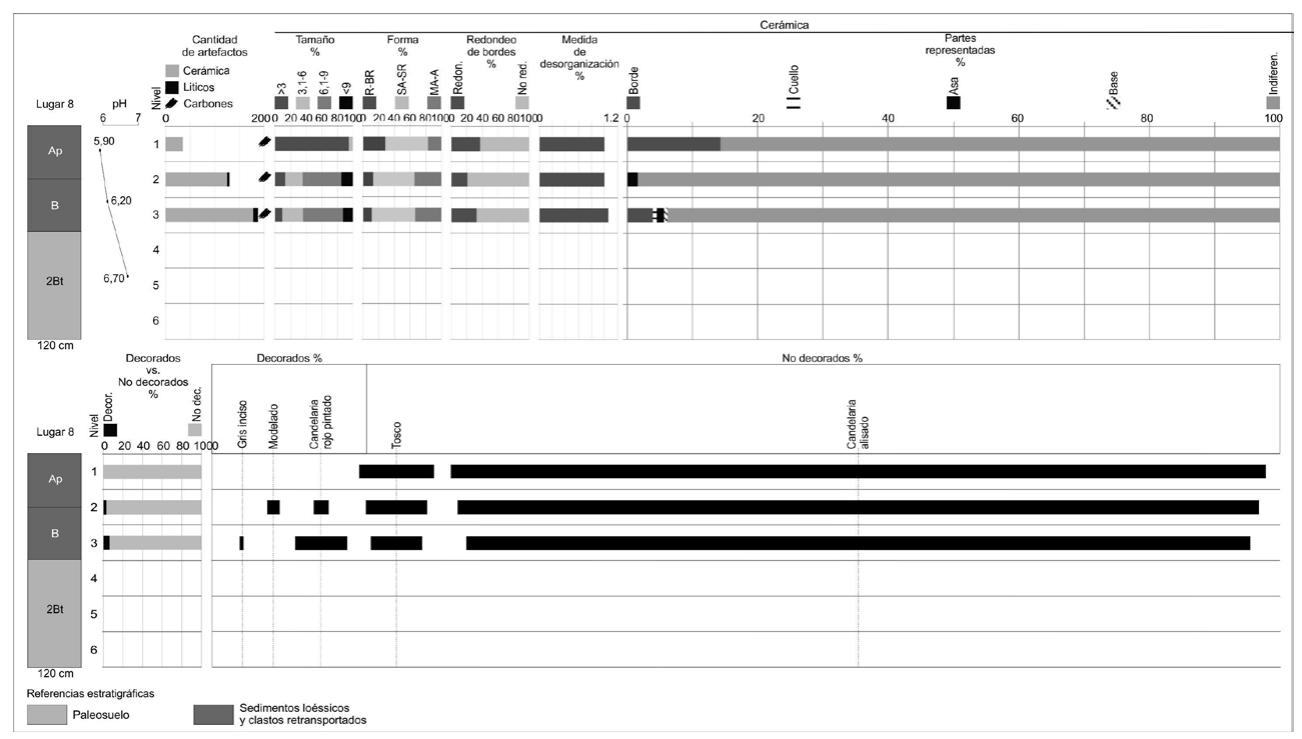

Figura 7. Variaciones estratigráficas de trazas de alteración, grupos y tipos cerámicos del Lugar 8.

Figure 7. Stratigraphic variations of traces of alteration, ceramic groups and types from Place 8.

alteración cerámica es mayor en el techo de la secuencia estratigráfica con amplio predomino de tiestos $<3 \mathrm{~cm}$, de formas bien redondeadas/redondeadas y con bordes redondeados. Contrariamente, en los niveles inferiores predominan los tiestos de 3,1-6 cm, 6,1-9 cm y $>9 \mathrm{~cm}$ y con bordes no redondeados (Figura 7).

Tipológicamente predominan los tiestos no decorados, principalmente Candelaria alisado y en menor medida los del grupo Tosco. Entre los decorados se identificaron fragmentos Gris inciso, Modelado y Candelaria rojo pintado. Los decorados están representados en los niveles 2 y 3 , donde se hallan los conjuntos más grandes (Figura 7).

Los resultados permiten inferir que los conjuntos arqueológicos fueron movilizados por procesos de escorrentía superficial, principalmente los de la parte superior de la secuencia donde además incidió el arado fragmentando y desplazando tiestos. Contrariamente, en la parte inferior de la secuencia los artefactos son más frecuentes y fueron menos movilizados considerando el predomino de tiestos de entre 3,1-6 cm a $>9 \mathrm{~cm}$, con formas anguloso/muy anguloso, de bordes no redondeados y la mayor diversidad de partes cerámicas. En el nivel 3 se hallaron los fragmentos de un puco Candelaria alisado casi completo, dos tiestos con aplicaciones al pastillaje en forma de cejas y ojos grano de café con lágrimas incisas del grupo Modelado, fragmentos Candelaria rojo pintado y Tosco, nueve microlascas de cuarzo (cristal de roca) y una de cuarcita, dos piezas elipsoides aplanadas de $5 \times 3 \times 0,5 \mathrm{~cm}$ con extremos perforados en pizarra (¿cuentas?) y tres puntas de proyectil apedunculadas, dos confeccionadas sobre filita ${ }^{3}$ y una en cuarzo (cristal de roca).

\footnotetext{
${ }^{3}$ Esta materia prima no es la más apropiada por su fragilidad y esquistosidad, pero dichas puntas de proyectil son tipológicamente comparables a las de cuarzo.
}

La mayor frecuencia, variabilidad artefactual y asociación de las evidencias sobre el paleosuelo sugieren que allí se desarrolló un nivel de ocupación, con reensamblaje de cerámica y escasamente afectado por movimiento hídrico. Aplicando el principio de Mc Kellar (Schiffer 1996) la presencia de microlascas en cuarzo, en un contexto con un artefacto en la misma materia prima, sugiere que se trata de residuos en contexto primario que por su tamaño escaparon a la eventual limpieza, quedado retenidos en la matriz limo arcillosa. Pero debido a su tamaño pequeño, estas microlascas también pudieron ser introducidas por escorrentía hídrica al igual que los escasos tiestos $<3 \mathrm{~cm}$, muy redondeados/redondeados y de bordes redondeados de este nivel.

Finalmente, en el lugar 4 se excavó un sondeo de 1,50 $x$ 1,50 $\mathrm{m}$ de lado en niveles artificiales de $10 \mathrm{~cm}$. No se hallaron indicios de un nivel de ocupación, pero es de interés por sus indicadores cronológicos relativos y estratigrafía.

La secuencia estratigráfica, de 1,70 m de profundidad, presenta en su parte superior el suelo actual desarrollado con horizontes A1/A2/E/B/C y luego dos paleosuelos, uno compuesto por los horizontes $2 \mathrm{Bt} / 2 \mathrm{BC}$, y otro por el horizonte $3 B C$. Se documentaron heces de lombrices en el horizonte $A 1$, cutanes en los horizontes $E, B$, 2Bt, 2BC y $3 B C$, siendo plásticos y adhesivos estos tres últimos. Los valores de $\mathrm{pH}$ son fuertemente ácidos en los horizontes superficiales y progresivamente menos ácidos con la profundidad del suelo actual, pero nuevamente son medianamente ácidos en los paleosuelos (Figura 8).

A lo largo de toda la estratigrafía se recuperaron 1408 fragmentos cerámicos, 26 líticos y se registraron espículas de carbón. Se documentó la presencia de material cultural actual en los primeros dos horizontes. La frecuencia de tiestos aumenta en sentido estratigráfico ascendente, también su alteración con el incremento progresivo de 


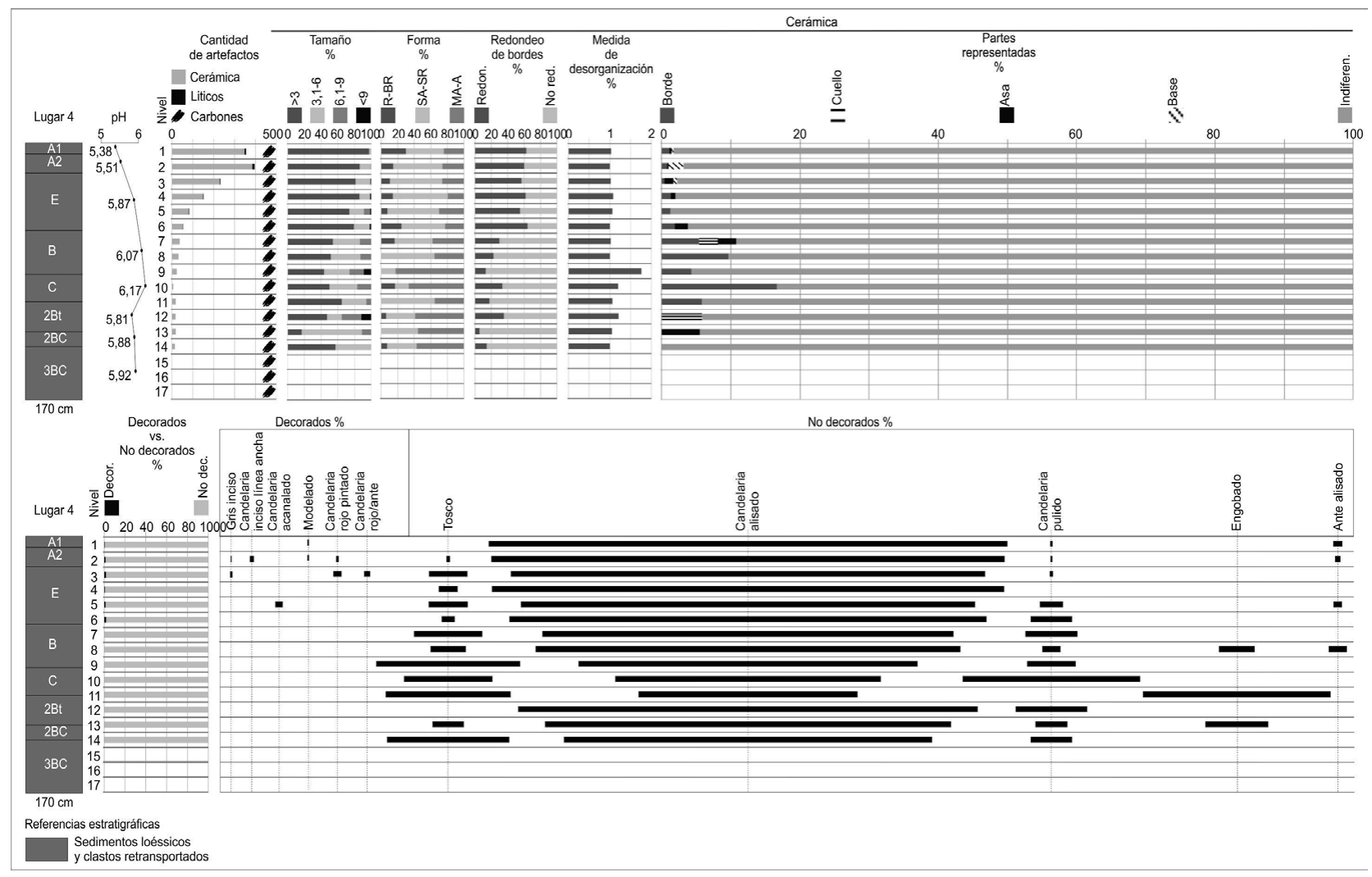

Figura 8. Variaciones estratigráficas de trazas de alteración, grupos y tipos cerámicos del Lugar 4.

Figure 8. Stratigraphic variations of traces of alteration, ceramic groups and types from Place 4.

la proporción de fragmentos $<3 \mathrm{~cm}$, de formas bien redondeados/redondeados y bordes redondeados. Casi no se reensamblaron tiestos, como lo señalan los bajos valores de medida de desorganización. Las tendencias indican procesos de transporte hídrico y sedimentación progresiva a través del tiempo (Figura 8). Entre los niveles 1 a 7 se documentaron trazas de raíces descompuestas (root casts), unas pocas de ellas de hasta $10 \mathrm{~cm}$ de diámetro con espículas de carbón y de tiestos, evidenciando algún movimiento descendente de materiales culturales.

La mayoría de tiestos no presentan decoración. Corresponden principalmente al tipo Candelaria alisado, cuya frecuencia se incrementa en sentido estratigráfico ascendente mientras que se reduce paralelamente las de Tosco, Candelaria pulido y Engobado. Esta tendencia se explica por el incremento en la alteración de los tiestos en dicha dirección estratigráfica, con eliminación del pulido y del engobe por erosión y la alta fragmentación que dificulta reconocer los tiestos tos $\cos ^{4}$, reduciéndose la representación de estos hasta casi la desaparición e incrementándose inversamente la de los alisados. Los escasos fragmentos decorados (Candelaria inciso línea ancha, Candelaria acanalado, Modelado, Candelaria rojo pintado y Candelaria rojo/ante) están presentes en la parte superior de la secuencia donde los conjuntos

\footnotetext{
${ }^{4}$ Los fragmentos toscos fueron reconocidos principalmente por la unión visible de las tiras de arcilla en la cara externa, que casi no se ven en fragmentos menores a $2 \mathrm{~cm}$.
}

cerámicos son más grandes. Este fenómeno se repite en los demás lugares excavados, por lo que se infiere que los fragmentos decorados aparecen más representados en los conjuntos cerámicos más grandes por su baja frecuencia original.

Por consiguiente, las variaciones verticales en la presencia/ausencia y las frecuencias de los tipos y grupos cerámicos no responden a cambios temporales sino a procesos de formación naturales (Figura 8).

\section{Discusión}

Las evidencias de ocupación analizadas se hallan en el sector distal del abanico aluvial del río Muerto (Figura 2), sobre un paleosuelo desarrollado en sedimentos limosos, con un horizonte $\mathrm{B}$ bien diferenciado. Coincidentemente, en una de las Lomas de Imbaud se documentó un nivel de ocupación sobre un paleosuelo desarrollado con horizontes A1/A2/B/Bt (Míguez 2005: 61-63; Miguez y Cuenya 2009). Este paleosuelo indica condiciones paleoclimáticas húmedas, como se propone para regiones vecinas. En el valle de Tafí, se identificó un paleosuelo datado en $2480 \pm 110$ AP (Peña Monné y Sampietro Vattuone 2016), así como en la cuenca de Tapia-Trancas (Caria y Sayago 2008), sobre los cuales se asientan las ocupaciones tempranas, y se documentaron paleosuelos en la llanura tucumano-santiagueña datados en $2840 \pm 60$ 
AP, $2660 \pm 50$ AP y $3040 \pm 40$ AP y (Sayago et al. 2003).

Luego del abandono de las ocupaciones, gradualmente se depositaron sedimentos de matriz limo arcillosa con materiales arqueológicos arrastrados por escorrentía superficial desde las partes más altas del abanico, proceso que enterró y preservó los contextos arqueológicos. Esta acumulación gradual se manifiesta en la creciente alteración de los fragmentos cerámicos en sentido estratigráfico ascendente en todas las unidades de procedencia analizadas. Sobre estos depósitos se desarrolló el suelo actual. Esta interpretación coincide con la observación de Schiffer (1996) respecto a la conservación de sitios o partes de ellos al quedar enterrados por una sedimentación natural gradual, lo cual tiene contrapartida en la erosión de otros sectores. En el lugar 7 la ocupación arqueológica fue cubierta por grava.

Los horizontes de suelo presentan condiciones entre fuertemente ácidas a débilmente ácidas, con valores de $\mathrm{pH}$ de entre 5,38 y 6,47 (con sólo tres valores neutros de $6,53,6,70,6,87)$. En todos los perfiles el grado de acidez disminuye con la profundidad alcanzando en algunos casos la neutralidad, lo cual puede tener relación con el consumo de bases por parte de las raíces, el lavado de nutrientes por el agua en sedimentos de los horizontes superficiales y una mayor retención de nutrientes en los horizontes arcillosos más profundos donde el desarrollo radicular es escaso o nulo.

La acción biológica favorecida por un ambiente húmedo pasado (inferido a partir de los rasgos macromorfológicos de los perfiles pedológicos) y presente (Grau et al. 2010; Santillán de Andrés y Ricci 1980) degradó ecofactos y potenciales artefactos de composición orgánica. La acidez debió degradar principalmente materiales orgánicos de los horizontes más superficiales, dado que en el paleosuelo el pH varía entre débilmente ácido y neutro, con algún grado de preservación de huesos humanos en urnas (Colaneri et al. 2003; Míguez et al. 2013). Las trazas de raíces descompuestas (root casts) con material arqueológico en su interior (lugar 4) indican procesos de floraturbación (Butzer 1989: 110-111; Schiffer 1996) aunque no se registraron masivamente, mientras que la presencia de lombrices y de sus heces en los perfiles descriptos evidencian faunaturbación (Canti 2003; Stein 1983) no obstante su incidencia no fue alta (a nivel macroscópico) considerando la distribución vertical de los artefactos y la diferenciación de capas y horizontes. No se documentaron indicadores de actividad de roedores.

Se infirió el desplome de una estructura arquitectónica de barro sobre una superficie de ocupación arqueológica en el lugar 3, que enterró y preservó el contexto. Estos procesos son responsables de impresionantes acumulaciones de sedimentos sobre el piso, contribuyendo significativamente a la formación de sedimentos arqueológicos (Schiffer 1996). Por consiguiente, es posible la repetición de este fenómeno sobre otros niveles de ocupación de Horco Molle. En el área cumbral de las Lomas de Imbaud se identificó un piso de ocupación arqueológica fuertemente compactado (de $9 \mathrm{~cm}$ de potencia), del cual se analizaron peso específico real y aparente, porosidad y contenido de materia orgánica (Míguez y Cano 2006; Miguez y Cuenya 2009). Dado que la sola compactación no prueba que se trate de un piso y que no se ha descripto claramente la posición de los materiales arqueológicos respecto al mismo, planteamos como posibilidad que podría corresponder en realidad a los restos de una estructura en barro derrumbada. Entre los niveles analizados en el presente trabajo no se documentaron pisos de ocupación muy evidentes, solamente una superficie levemente endurecida (de $3 \mathrm{~mm}$ de espesor) por debajo de la vasija aplastada del lugar 3 , en un contexto con evidencias de alteración térmica.

Además de los procesos naturales mencionados, otros de índole antrópica incidieron en las formas de deposición y de disturbación de los contextos.

Dado que la disponibilidad de recursos para la elaboración de alfarería y de artefactos líticos condiciona el asentamiento de grupos humanos sedentarios (Olivera 2001), es esperable la influencia de dicha disponibilidad en un bajo costo de reemplazo y en un alto grado de descarte de artefactos en materias primas locales, con la consecuente acumulación de desechos secundarios o de residuos de facto, así como la escasez o ausencia de procesos de reuso o reclamación. Ese parece ser el caso de Horco Molle, donde hay disponibilidad local de materias primas (arcillas y filita) (Mon y Suayter 19721974; Sesma et al. 2010) para elaborar alfarería casi exclusivamente ordinaria, con variedades de colores que indican posiblemente cocción a cielo abierto (Rye 1981) y destinada a satisfacer necesidades domésticas inmediatas, lo cual pudo influir en la ausencia de indicadores de reuso y reclamación con la posible excepción de las vasijas más grandes como se explica más adelante. Para elaborar puntas de proyectil de limbo triangular y base escotada se emplearon materias primas locales (cuarzo y filita) y para artefactos de filo natural y/o formatizado se usó material local y foráneo (cuarcita, sílice, calcedonia, vulcanita y arenisca) (Cano 2002; Maldonado et al. 2011; Míguez y Gramajo Bühler 2007), con un solo caso de reciclaje de un instrumento compuesto (raclette + muesca + perforador) en sílice, materia prima alóctona.

Además de estas consideraciones, algunas formas específicas de deposición registradas requieren tener en cuenta otros factores.

Para el entierro del lugar 7, la presencia de las cuentas líticas de materiales alóctonos (Ruíz 2003) respondería a su alto costo de reemplazo y características ornamentales, siendo objetos hallados frecuentemente en contextos 


\begin{tabular}{|c|c|c|c|c|c|c|c|c|c|c|c|}
\hline \multicolumn{12}{|c|}{ Horco Molle } \\
\hline $\begin{array}{l}\text { Fases } \\
\text { (Años DC) }\end{array}$ & $\begin{array}{l}\text { Tipos } \\
\text { Cerámicos }\end{array}$ & 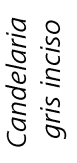 & 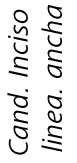 & 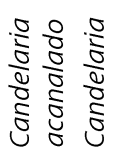 & $\begin{array}{r}\frac{0}{8} \\
\frac{8}{5} \\
\frac{8}{0} \\
\frac{1}{6}\end{array}$ & $\begin{array}{ll}0 & 0 \\
\frac{2}{0} & \frac{0}{0} \\
\frac{0}{2} & \frac{0}{0} \\
0 & 0 \\
0 & \varepsilon\end{array}$ & $\begin{array}{l}\frac{0}{0} \\
\frac{0}{0} \\
\frac{0}{0} \\
\frac{0}{0} \\
\frac{1}{2} \\
\frac{1}{0} \cdot \frac{0}{0}\end{array}$ & $\begin{array}{ll}\frac{0}{2} & \frac{0}{5} \\
\frac{0}{0} & \frac{0}{0} \\
\frac{0}{0} & \frac{0}{2}\end{array}$ & 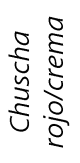 & $\begin{array}{l}\frac{0}{2} \\
\frac{0}{0} \\
\frac{0}{0} \\
\frac{0}{0} \\
\frac{0}{0} \\
0\end{array}$ & 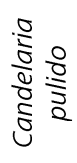 \\
\hline S. Bárbara & 1000 & & $\mathrm{X}$ & & $\mathrm{X}$ & & & & & $X$ & $x$ \\
\hline Quebrachal & $700-$ & $x$ & & & $x$ & & & & & $X$ & $x$ \\
\hline Rupachico & 1000 & & & $x$ & $x$ & & & & & $x$ & $x$ \\
\hline Molleyaco & חמר_חמת & $x$ & & $x$ & $x$ & & & $x$ & & $x$ & $x$ \\
\hline Choromoro & $400-100$ & $x$ & $x$ & $x$ & $x$ & $x$ & $x$ & $x$ & & $X$ & $x$ \\
\hline Chuscha & $200-400$ & $x$ & $x$ & $x$ & $x$ & $x$ & $x$ & $x$ & $x$ & $x$ & $x$ \\
\hline
\end{tabular}

Tabla 2. Tipos cerámicos identificados en los contextos analizados y su representación en las fases de Candelaria establecidas por Heredia (1975).

Table 2. Ceramic types identified in the contexts analyzed and their representation in the phases of Candelaria established by Heredia (1975).

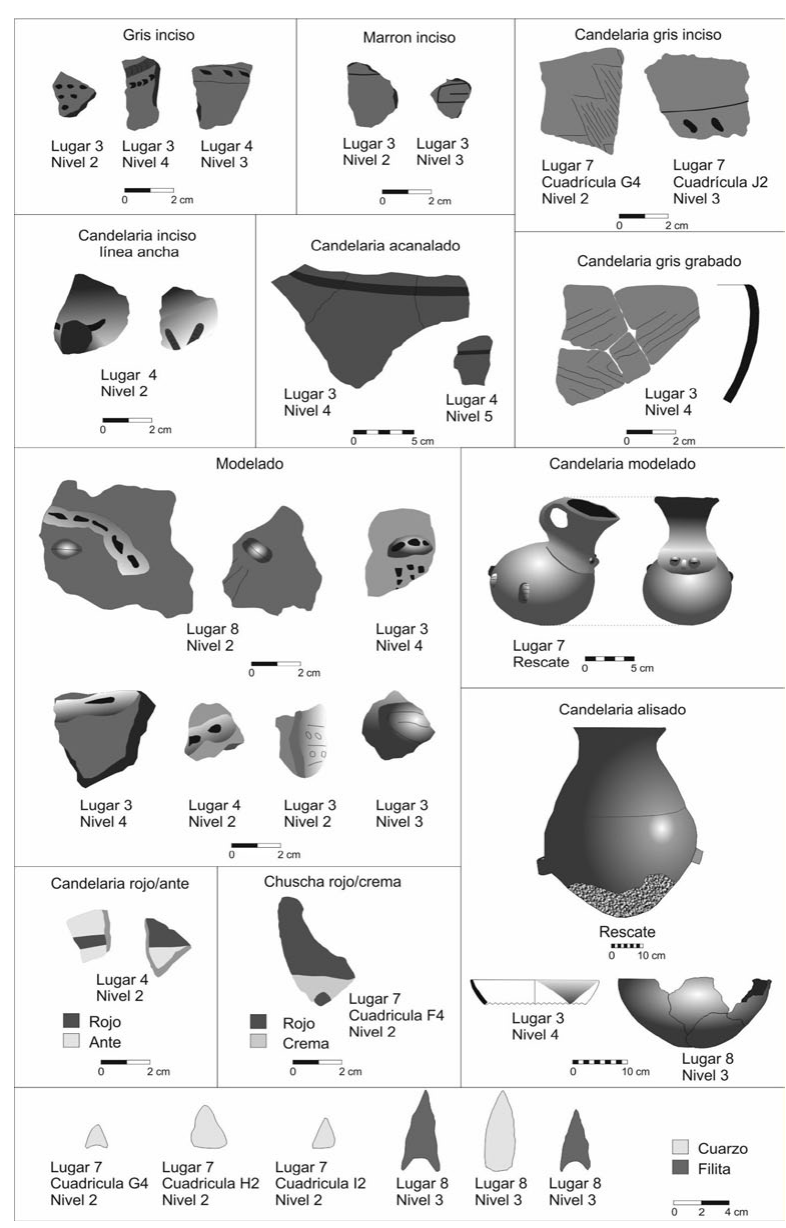

Figura 9. Tipos, grupos cerámicos y puntas de proyectil de los contextos excavados en Horco Molle.

Figure 9. Types, ceramic groups and projectile points from the contexts excavated in Horco Molle.

funerarios (Berberián et al. 1977: 37; Heredia 1971: 28), al igual que la vasija zooantropomorfa Candelaria modelado que no son frecuentes en los conjuntos cerámicos y se hallan comúnmente en entierros (Heredia 1975: 88; Ryden 1936). Respecto al contenido óseo, considerando los valores de $\mathrm{pH}$ variablemente ácidos del lugar, es llamativa la presencia de huesos susceptibles a la degradación (costillas, vértebras) y la ausencia de otros menos aptos (fémur, húmero), así como la mayor proporción de partes del individuo de menor rango etario (Colaneri et al. 2003) dado que mientras menor es la edad mayor es la susceptibilidad a la degradación en un medio ácido (Gordon y Buikstra 1981). Sumado a que los restos se hallaron mezclados en el fondo de la urna, hipotéticamente se trataría de entierros secundarios (Colaneri com pers), inferencia que se repite para otros entierros de Horco Molle (Míguez et al. 2013) y de Selvas Occidentales meridionales (Baldini et al. 2003; Heredia 1971: 28 y 30).

Adicionalmente, puede proponerse como hipótesis que las urnas funerarias de Horco Molle serían vasijas reusadas de previo uso doméstico, dado el agregado funcional de revoque en su base para asegurar su estabilidad vertical, modalidad técnica documentada en cerámicas de los niveles de ocupación analizados. El entierro de los tres infantes en una única urna implicaría asimismo una maximización de sus posibilidades de uso. Coincidentemente, en Las Pirguas se documentaron entierros múltiples en urna, algunas son vasijas ordinarias con hollín en sus partes externas y en ocasiones presentan el cuello seccionado para introducir los restos (Baldini et al. 2003).

Respecto a los niveles de ocupación en grupos sedentarios, dada la permanencia prolongada y la variedad de actividades, el mantenimiento de áreas de actividad tiende a ser organizado, exhaustivo, a intervalos regulares, removiendo grandes piezas y dejando pequeños ítems, aunque en las fases de abandono quedan depósitos de desechos primarios y de facto por la relajación de los estándares de limpieza (Tani 1995).

En el nivel de ocupación del lugar 3 se depositaron como desechos de facto una vasija Candelaria acanalado con un alto grado de deterioro (fisuras, descascarado de la superficie interna con adelgazamiento de las paredes) y un molino, ambos realizados en materias primas locales, voluminosos y pesados, condiciones físicas que junto con la distancia de transporte son causas del abandono de forma permanente ${ }^{5}$ (Joyce y Johannessen 1996; La Motta y Schiffer 1999). En el marco de un sistema adaptativo formativo es esperable, dado su tamaño y peso, que

\footnotetext{
${ }^{5}$ Una forma de transporte para vasijas voluminosas y pesadas es sugerida por las estatuillas de estilos Candelaria, San Francisco y Vaquerías, en las cuales una mujer carga una vasija sobre sus espaldas (González 1998).
} 


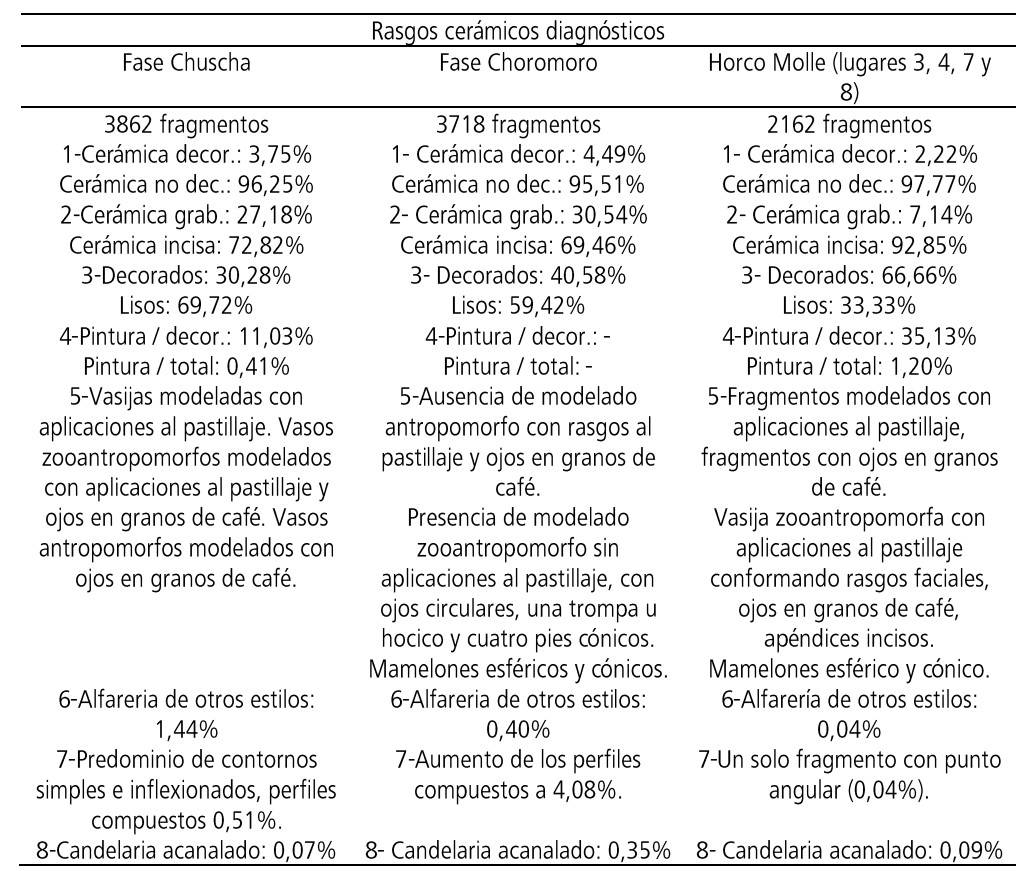

Tabla 3."Rasgos diagnósticos" de la cerámica de las fases Chuscha y Choromoro (Heredia 1975) y su análisis para los contextos analizados.

Table 3. "Diagnostic features" of ceramics of the Chuscha and Choromoro phases (Heredia 1975) and their analysis for the contexts analyzed.

elementos relativos a la tecnología productiva (por ejemplo, molinos y morteros de piedra) fueran dejados en los sitios aún ante un abandono definitivo, así como también que estos alcancen un alto grado de desgaste dado que las tecnologías de mayor vida útil se asocian a la permanencia prolongada en un asentamiento (Olivera 2001).

Los residuos más pequeños, si no fueron limpiados de un área de actividad, pudieron ser sometidos a procesos de pisoteo. La cantidad de pisoteo depende de la intensidad de ocupación de un sitio, relacionados con el grado de movilidad y sedentarismo de los sistemas adaptativos formativos (Olivera 2001; Pintar 1989; Tani 1995). En los niveles de ocupación analizados predominan los tiestos < $3 \mathrm{~cm}$ mezclados con fragmentos $>9 \mathrm{~cm}$, en coincidencia con los patrones de tamaño generados por procesos de pisoteo según Nielsen (1991). En los conjuntos afectados por procesos de escorrentía hídrica superficial también prevalecen los tiestos $<3 \mathrm{~cm}$, pudiendo implicar que fueron previamente pisoteados, pero la fragmentación es más generalizada dado que son menos frecuentes los tiestos de las categorías de mayores dimensiones.
La reducción de tamaño es aún mayor en donde además de los procesos mencionados incidió el arado, como sucede en el techo de la secuencia del lugar 8.

Dejando de lado los procesos de formación de los niveles de ocupación analizados, es posible lograr una aproximación a sus cronologías discutiendo los datos estilísticos de la cerámica y el fechado obtenido.

Los niveles de ocupación analizados comparten algunos tipos y grupos cerámicos tales como Gris inciso, Modelado, Candelaria rojo pintado, Tosco, Candelaria alisado, Candelaria pulido y Ante alisado. Sin embargo, en el conjunto total de la muestra también están presentes otros tipos y grupos cerámicos de valor cronológico (Figura 9).

La variedad de tipos cerámicos registrados en los niveles de ocupación de Horco Molle está particularmente representada en lo que Heredia (1975) definió como fases Chuscha (200-400 DC) y Choromoro

(400-700 DC) de Candelaria ${ }^{6}$ (Tabla 2). Los conjuntos de tiestos analizados presentan mayores similitudes con los "rasgos cerámicos diagnósticos" establecidos por dicho autor para la fase Chuscha ( $N^{\circ} 1,2,5,7$ y 8 ) que con los de la fase Choromoro (Tabla 3), aunque son sutiles de las diferencias entre los rasgos de ambas fases.

La estimación cronológica de las ocupaciones, obtenida a partir de las características de la cerámica, se refuerza con el fechado radiocarbónico de $1639 \pm 57$ AP (AA104699) que obtuvimos del nivel de ocupación del lugar 3 , y el de $1420 \pm 20 \mathrm{AP}$ (UGA22275) procedente del contexto funerario del lugar 7 (Míguez y Caria 2016: 2022), cuyas calibraciones coinciden con los finales de la fase Chuscha y la fase Choromoro. Sin embargo Míguez y Caria (2016: 16) obtuvieron un fechado de $2190 \pm 20$ AP (UGA22274) a partir de hueso humano de un contexto funerario

\footnotetext{
${ }^{6}$ Aunque la secuencia de Heredia (1975) casi no tiene dataciones radiocarbónicas que sustenten las fechas que definen cada fase, no carece de valor cronológico relativo dado que se apoya en superposiciones estratigráficas y dataciones cruzadas. Aquí se la toma como una referencia, que se confronta con los resultados de nuestra investigación.
}

Figura 10. Fechados radiocarbónicos obtenidos para la localidad arqueológica de Horco Molle.

Figure 10. Radiocarbon dates obtained for the archaeological locality of Horco Molle.

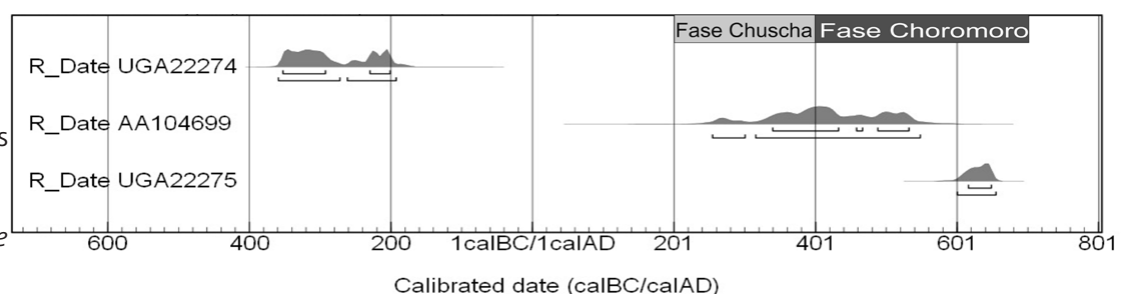

Calibrated date (calBC/calAD) 
excavado a las orillas del arroyo Anta Yacu (Figura 10). Los autores señalaron que la cerámica registrada allí es homogénea, poco elaborada y sin decoración, la que se distingue de la alfarería de la "zona de Horco Molle" (es decir, donde realizamos los sondeos y excavaciones de este trabajo), aunque no presentaron datos más específicos que nos permitan efectuar una comparación.

La discusión efectuada permite proponer la presencia de grupos humanos aldeanos en la localidad arqueológica de Horco Molle entre ca. 350 AC y ca. 650 DC. Complementariamente, en Horco Molle se documentaron algunos tiestos pintados comparables a los de estilo Aguada y que en términos locales corresponderían al Rupachico polícromo de Heredia (1975: 129, Figura 14 a-d), así como cerámica fina negra pulida con reticulados incisos (Míguez 2005: 93-94, 102 y 114), cerámicas representadas en las fases Molleyaco (400-700 DC) y/o Rupachico (700-1000 DC) de la propuesta cronológica de Heredia (1975).

Fuera de la localidad arqueológica de Horco Molle, se registraron contextos de ocupación con cronologías y contenidos comparables tanto en Selvas Occidentales meridionales como en regiones vecinas.

El sitio Bajada de la Ovejería, ubicado al O de la sierra de San Javier (valle de La Sala), fue asignado a la fase Chuscha (200-400 DC) dado el hallazgo en excavación de un fragmento Condorhuasi polícromo y tiestos con ojos en granos de café al pastillaje y lágrimas incisas (Angiorama et al. 1992). Más hacia el NO en El Siambón, Heredia (1975) registró al sitio T1 al cual definió como "típicamente Condorhuasi", y los sitios T3 y T6 que asignó a la fase Choromoro (400-700 DC) por las características de la cerámica, pero no efectuó excavaciones de niveles de ocupación. Sólo realizó sondeos en una estructura residencial del sitio T 13 situado más al $\mathrm{N}$ en la localidad de Choromoros, donde detectó dos niveles de ocupación superpuestos que le permitieron diacronizar las fases Chuscha y Choromoro y establecer sus diferencias cerámicas (Tabla 3), aunque no obtuvo fechados radiocarbónicos. Este autor también asignó a la fase Choromoro a los niveles de ocupación documentados por Krapovickas (1968) en una estructura residencial de Alto de Medina, pero exclusivamente sobre la base de las características estilísticas de la cerámica. Considerando lo expresado, los contextos de ocupación de Horco Molle tienen la particularidad de que, además de presentar conjuntos cerámicos con características similares a las que identifican a las fases Chuscha y Choromoro, proporcionan fechados coincidentes con la cronología de esas fases (Figura 10). Cabe destacar que casi la totalidad de las dataciones conocidas que cubren el rango temporal de dichas fases proceden de contextos funerarios aislados u otros removidos (Fasth 2003; Heredia 1971; Muñoz 2002; Ryden 1936).
Complementariamente, en Selvas Occidentales meridionales es frecuente el hallazgo en superficie de puntas de proyectil de limbo triangular y base escotada (Miguez y Caria 2010: Figura 4, Lámina 15; Reyes Gajardo 1952-1954: Figura 66c) pero es esporádico su registro en excavación y con fechados asociados. Se documentó su presencia en contextos asignados a las fases Chuscha (200-400 DC) y Molleyaco (400-700 DC) aunque sin dataciones (Heredia 1971: 100; Heredia 1975: 90). En Horco Molle encontramos puntas de base escotada en los niveles de ocupación de los lugares 7 y 8 (Figura 9), en el primero de ellos con un fechado de $1420 \pm 20$ AP (de su contexto funerario) lo cual, junto con su registro en entierros con cerámica Candelaria datados en 910 \pm 100 AP (Berberián et al. 1977), permite vislumbrar un marco temporal que deberá investigarse. Puntas de limbo triangular y base escotada también se hallaron en contextos tardíos del área (Esparrica 1999: 219).

De forma similar a Horco Molle en Selvas Occidentales meridionales, la asociación de cerámica decorada al pastillaje con cejas y ojos en granos de café, modelados zoomorfos, tiestos finos gris incisos o grabados, fragmentos monocromos rojos y puntas de proyectil triangulares de base escotada en cuarzo y obsidiana fue documentada por ejemplo en niveles de ocupación de los valles de La Ciénega (Cremonte 1996), Santa María (Palamarczuk et al. 2007) y El Cajón (Scattolin et al. 2009) con dataciones correspondientes a la mitad inicial del primer milenio de la Era Cristiana. Apoyando estas observaciones, Scattolin (2007) encontró similitudes en la cultura material temprana de las regiones mencionadas, y propuso una secuencia cronológica única para ellas. Considerando las dataciones y las características estilísticas de la cerámica, en Horco Molle estarían representadas las fases Chimpa (100-450 DC) y Bañado (450-650 DC) de dicha secuencia, equivalentes con las fases Chuscha (200-400 DC) y ChoromoroMolleyaco (400-700 DC) de la secuencia de Heredia (1975) (Scattolin 2007: Figura 7).

\section{Conclusiones}

En la localidad arqueológica de Horco Molle, en sector distal del abanico aluvial del río Muerto, se registraron tres niveles de ocupación sobre un paleosuelo desarrollado en sedimentos limosos con horizontes B iluviales. Estos contextos arqueológicos fueron enterrados y preservados por la sedimentación de limos arcillosos con materiales arqueológicos arrastrados por procesos de escorrentía superficial, sobre los cuales se desarrolló el suelo actual. En un caso la ocupación arqueológica fue cubierta por grava. Ello determinó que los fragmentos cerámicos fueran progresivamente alterados en sentido estratigráfico ascendente.

La acción biológica favorecida por condiciones húmedas pasadas y presentes degradaron ecofactos y potenciales 
artefactos de composición orgánica, con la colaboración en mayor o menor medida de suelos fuertemente a débilmente ácidos. La penetración y descomposición de raíces generó procesos de floraturbación y la actividad de lombrices faunaturbación, pero su incidencia en los contextos arqueológicos fue mínima.

Se infirió el desplome de una estructura arquitectónica de barro sobre una superficie de ocupación arqueológica del lugar 3, enterrando y preservando el contexto con desechos de facto posiblemente abandonados por su alto grado de deterioro, por ser de materias primas locales, voluminosos y pesados. En la ocupación del lugar 7 se halló un nivel cultural con una acumulación de arcilla, tiestos y puntas de proyectil, y por debajo un entierro secundario de infantes en urna funeraria con cuentas líticas y una vasija zooantropomorfa, objetos de alto costo de reemplazo y que no se hallan en contextos domésticos. En el nivel de ocupación del lugar 8 se encontraron puntas de proyectil, microlascas, posibles cuentas en roca metamórfica y un puco. Los fragmentos cerámicos de estos contextos fueron sometidos a procesos de pisoteo.

La variedad de tipos cerámicos registrados en los niveles de ocupación de Horco Molle está particularmente representada en lo que se conoce como fases Chuscha (200-400 DC) y Choromoro (400-700 DC), estimación cronológica que coincide con el fechado radiocarbónico de $1639 \pm 57$ AP (AA104699) obtenido para el nivel de ocupación del lugar 3 y el de $1420 \pm 20$ AP (UGA22275) procedente del contexto funerario del lugar 7.

El trabajo efectuado en Horco Molle es una contribución a la problemática del déficit de datos acerca de las características y cronología de niveles de ocupación prehispánicos en Selvas Occidentales meridionales, como contrapartida al hallazgo y datación casi exclusiva de contextos funerarios aislados. Aportes de este tipo permitirán a futuro reevaluar los cambios temporales de la cultura material que se han indicado hasta el momento.

La perspectiva geoarqueológica y de procesos de formación de sitios aplicadas en Horco Molle a través de nuestras sucesivas investigaciones genera nuevas expectativas para el hallazgo de contextos de ocupación relativamente preservados y con posibilidades de ser fechados a partir del conocimiento de paisajes geomorfológicamente heterogéneos y sus dinámicas, lugares con importantes procesos de erosión facilitados por el cultivo extensivo de los suelos y bajo condiciones climáticas subtropicales.

San Miguel de Tucumán, 11 de Noviembre de 2016

\section{Agradecimientos}

Este trabajo fue solventado por la Secretaría de Ciencia y Técnicas (UNT) proyecto CIUNT 26/G440.

\section{Bibliografía}

Angiorama, C. I., M. A. Caria, L. A. Moya y C. Taboada. 1992. Bajada de La Ovejería: un sitio Candelaria. II Congreso Nacional de Estudiantes de Arqueología. Rosario.

Aschero, C. 1975. Ensayo para una clasificación morfológica de artefactos líticos aplicada a estudios tipológicos comparativos. Informe al CONICET. Ms.

Aschero, C. 1983. Ensayo para una clasificación morfológica de artefactos líticos aplicada a estudios tipológicos comparativos. Apéndices A-C. Revisión. Cát. de Ergología y Tecnología. Facultad de Filosofía y Letras, Universidad Nacional de Buenos Aires). Ms.

Baldini, M. I., E. I. Baffi, M. T. Salaberry y M. F. Torres. 2003. Candelaria: una aproximación desde un conjunto de sitios localizados entre los cerros de Las Pirguas y El Alto del Rodeo (Dpto. Guachipas, Salta, Argentina). G. Ortíz y B. Ventura Editores, La Mitad Verde del Mundo Andino. Investigaciones arqueológicas en la vertiente oriental de Los Andes y las tierras bajas de Bolivia y Argentina, pp. 131-152: Universidad Nacional de Jujuy, San Salvador de Jujuy.

Berberián, E. E., J. García Azcárate y M. Caillou. 1977. Investigaciones arqueológicas en la región del Dique El Cadillal (Tucumán-Rep. Argentina). Los primeros fechados radiocarbónicos. Relaciones de la Sociedad Argentina de Antropología, XI: 31-52.

Binford, L. R. 1982. The archaeology of place. Journal of Anthropological Archaeology, 1 (1): 5-31.

Bloom, A. L., 1998. La superficie de la tierra. Omega. Barcelona.

Butzer, K. W. 1989. Arqueología- una ecología del hombre: método y teoría para un enfoque contextual. Bellaterra. Barcelona.

Cano, S. F. 2002. Aproximación al estudio de los procesos de formación de sitios en el área pedemontana de la Sierra de San Javier: análisis preliminar del sitio STucYeb 2 (Depto. Yerba Buena, Tucumán). VII Congreso Nacional de Estudiantes de Arqueología. San Pedro de Colalao, Tucumán (ms).

Canti, M. G. 2003. Earthworm activity and archaeological stratigraphy: a review of products and processes. Journal of Archaeologial Science, 30: 135-148. http://alliance. la.asu.edu/rockart/scans/CantiEarthworms.pdf (Última consulta: 25/08/2016).

Caria, M. A., J. M. Sayago. 2008. Arqueología y ambiente en un valle intermontano del piedemonte oriental de las 
Cumbres Calchaquíes (Tucumán, Argentina). Runa, 29: 11-28. http://www.scielo.org.ar/pdf/runa/v29/v29a01. pdf (Última consulta: 25/08/2016).

Colaneri, M. G., A. Calisaya, A. Gerónimo, E. Milena, A. González, V. Vargas, S. Rodríguez, M. Contreras, L. Navarro, G. Guardia, W. Guerra, D. Ruiz y C. Gelsi. 2003. Análisis del material rescatado en Horco Molle. VI Jornadas de Comunicaciones. San Miguel de Tucumán.

Cremonte, M. B. 1996. "Investigaciones arqueológicas en la Quebrada de la Ciénaga (Dpto. de Tafí, Tucumán)". Facultad de Ciencias Naturales y Museo, Universidad Nacional de La Plata, Argentina. Tesis Doctoral. Facultad de Ciencias Naturales y Museo, Universidad Nacional de La Plata.

Esparrica, H. C. 1999. Nuevas evidencias arqueológicas acerca de la Tradición Santamariana en el piedemonte septentrional de la provincia de Tucumán. XIII Congreso Nacional de Arqueología Argentina. Córdoba.

Fasth, N. 2003. "La Candelaria. Preservation and conservation of an archaeological museum collection from North-western Argentina at the Museum of World Culture, Sweden". Department of Environmental Sciences and Conservation, Institut of Conservation, University of Göteborg, Suecia, pp. 49. Tesis de Magister. Department of Environmental Sciences and Conservation, Institut of Conservation, University of Göteborg.

González, A. R. 1977. Arte precolombino de la Argentina, introducción a su historia cultural. Filmediciones Valero. Buenos Aires.

González, A. R. 1998. Cultura La Aguada, arqueología y diseños. Filmediciones Valero. Buenos Aires.

Gordon, C. C., J. E. Buikstra. 1981. Soil pH, bone preservation, and sampling bias at mortuary sites. American Antiquity, 48 (3): 586-591.

Grau, H. R., L. Paolini, A. Malizia y J. Carrilla. 2010. Distribución, estructura y dinámica de los bosques de la sierra de San Javier (Tucumán, Argentina). H. R. Grau Editores, Ecología de una interfase natural-urbana. La sierra de San Javier y el Gran San Miguel de Tucumán, Capítulo 3 pp. 33-50, Universidad Nacional de Tucumán (EDIUNT), San Miguel de Tucumán.

Heredia, O. R. 1971. Excavaciones Arqueológicas en La Candelaria (Provincia de Salta). Etnia, 13: 25-35.

Heredia, O. R. 1975. Investigaciones Arqueológicas en el sector meridional de las Selvas Occidentales. Revista del Instituto de Antropología, 5: 73-132.

Joyce, A. A. y S. Johannessen. 1996. Abandonment and the production of archaeological variability at domestic sites. B. C. Cameron y S. Tomka Editores, Abandonment of settlements and regions. Ethnoarchaeological and archaeological approaches, Capítulo 11 pp 138-153, Cambridge University Press, Cambridge.

Krapovickas, P. 1968. Arqueología de Alto de Medina, Provincia de Tucumán, República Argentina. Rehue 1: 89-124.

La Motta, V. M. y M. Schiffer. 1999. Formation processes of house floor assemblages. P. M. Allison Editor, The Archaeology of Household Activities, Capítulo 2 pp. 1929, Routledge, London.

Maldonado, M. G., L. Del Valle Neder, J. Roldán y M. M. Sampietro Vattuone. 2009. Procesos de formación de sitios en el sector meridional de las Selvas Occidentales (sitio STucYeb 2 "Horco Molle", Yerba Buena, Tucumán, Argentina). Anales de Arqueología y Etnología, 63-64: 305-330.

Maldonado, M. G., L. Del Valle Neder, J. Roldán y M. M. Sampietro Vattuone. 2010a. Criterios, técnicas y estrategias geoarqueológicas de prospección en zonas selváticas de piedemonte y tierras bajas del NOA. S. Bertolino, R. Cattáneo y A. D. Izeta Editores, La Arqueometría en Argentina y Latinoamérica, pp. 391396, Facultad de Filosofía y Humanidades, Universidad Nacional de Córdoba. Córdoba.

Maldonado, M. G., J. Roldán, L. Del Valle Neder, y M. M. Sampietro Vattuone. 2010b. Valoración de atributos cerámicos para la evaluación de procesos de formación de sitios de tierras bajas del NOA. S. Bertolino, R. Cattáneo y A. D. Izeta Editores, La Arqueometría en Argentina y Latinoamérica, pp. 73-78, Facultad de Filosofía y Humanidades, Universidad Nacional de Córdoba. Córdoba.

Maldonado M. G., L. Del Valle Neder, J. Roldán y M. M. Sampietro Vattuone. 2011. Caracterización geoambiental y cultural del Período Formativo en Selvas Occidentales Meridionales: sitio "Horco Molle" (Dpto. de Yerba Buena, Tucumán). Comechingonia, 14: 41-57.

Míguez, G. E. 2005. "Dinámica local y relaciones interétnicas: nuevas investigaciones y replanteo de la problemática arqueológica del piedemonte de la Sierra de San Javier. Dpto. de Yerba Buena, Pcia. de Tucumán". Facultad de Ciencias Naturales e IML, Universidad Nacional de Tucumán, Argentina, pp. 135. Trabajo Final de la Carrera de Arqueología. Facultad de Ciencias Naturales e IML, Universidad Nacional de Tucumán.

Míguez, G. E. y S. F. Cano. 2006. La agonía de un sitio arqueológico: procesos postdepositacionales en el piedemonte oriental de la Sierra de San Javier (Horco 
Molle-Dpto. Yerba Buena-Tucumán). III Congreso Argentino de Cuaternario y Geomorfología. Córdoba.

Míguez, G. E. y M. Gramajo Bühler. 2007. Tallando en las tierras bajas de Tucumán: análisis de artefactos líticos de Horco Molle, Provincia de Tucumán. XVI Congreso Nacional de Arqueología Argentina, III. San Salvador de Jujuy.

Míguez, G. E. y Cuenya. 2009. Caracterización arqueopedológica de un piso de ocupación prehispánica en el sitio Horco Molle (Tucumán). IV Congreso Argentino de Cuaternario y Geomorfología. XII Congresso do Associaçao Brasileira de Estudos do Quaternário. II Reunión sobre el Cuaternario de América del Sur. La Plata.

Miguez, G. E. y M. A. Caria. 2010. La ocupación prehispánica de la sierra de San Javier y espacios aledaños (Tucumán, Argentina). H. R. Grau Editor, Ecología de una interfase natural-urbana. La sierra de San Javier y el Gran San Miguel de Tucumán, Capítulo 7 pp. 119135, Universidad Nacional de Tucumán (EDIUNT), San Miguel de Tucumán.

Míguez, G. E., M. J. Barazutti, R. A. Guerrero y A. Bertelli. 2013. Urnas en línea: análisis contextual de una práctica funeraria registrada en la zona de Horco Molle (Tucumán, Argentina). XVIII Congreso Nacional de Arqueología Argentina. La Rioja.

Miguez, G. E. y M. A. Caria. 2016. Nuevos aportes a la cronología de la ocupación prehispánicadel piedemonte oriental de la sierra de San Javier (Tucumán): primeros fechados absolutos. XIX Congreso Nacional de Arqueología Argentina. San Miguel de Tucumán

Mon, R., L. E. Suayter. 1972-1974. Geología de la Sierra de San Javier (Provincia de Tucumán, República Argentina). Acta Geológica Lilloana, 12: 157-168.

Muñoz, A. 2002. Informe sobre dataciones de La Candelaria. Manuscrito. Göteborg. Ms.

Nastri, J. 1997-1998. Patrones de asentamientos prehispánicos tardíos en el sudoeste del valle de Santa María (Noroeste Argentino). Relaciones de la Sociedad Argentina de Antropología XXII-XXIII: 247-270.

Nielsen, A. E. 1991. Se hace camino al andar. Estudio experimental sobre patrones de fractura en material cerámico sometido a pisoteo. Shincal, 3 (I): 116-139.

Olivera, D. E. 2001. Sociedades agropastoriles tempranas: el Formativo Inferior del Noroeste Argentino. E. E. Berberían y A. E. Nielsen Directores, Historia Argentina Prehispánica, pp. 83-125, Brujas, Córdoba.

Palamarczuk, V., R. Spano, F. Weber, D. Magnífico, S.
López y M. Manasiewicz. 2007. Soria 2. Apuntes sobre un sitio formativo en el valle de Yocavil (Catamarca, Argentina). Intersecciones en Antropología, 8: 121-135. http:// www.scielo.org.ar/pdf/iant/n8/n8a09.pdf (Última consulta: 25/08/2016).

Peña-Monné, J. L. y M. M. Sampietro Vattuone. 2016. La secuencia paleoambiental holocena de la vertiente oriental de la Loma Pelada (valle de Tafí, Noroeste Argentino): cambios climáticos y acción humana. M. M. Sampietro Vattuone y J. L. Peña Monné Editores, Geoarqueología de los Valles Calchaquíes. Ocupaciones Humanas y Reconstrucciones Paleoambientales del Holoceno, pp. 23-63, Universidad Nacional de Tucumán, San Miguel de Tucumán.

Pintar, E. L. 1989. Una experiencia de pisoteo: perturbación del registro arqueológico? Shincal, I: 6171.

Primera Convención Nacional de Antropología. 1966. I Convención Nacional de Antropología, Primera Parte. Instituto de Antropología, Publicaciones, Nueva Serie I (26). Córdoba.

Rapp, G. y C. Hill. 1998. Geoarchaeology. Yale University Press. New Haven and London.

Reyes Gajardo 1952-1954. Estudio sobre Choromoros. Revista del Instituto de Antropología VII (2). Universidad Nacional de Tucumán, San Miguel de Tucumán.

Ruiz, N. D. 2003. Análisis del ajuar de dos urnas funerarias. VI Jornadas de Comunicaciones. San Miguel de Tucumán.

Ryden, S. 1936. Archaeological research in the departament of Candelaria. Etnologiska Studier, 3: 5- 320.

Rye, O. S. 1981. Pottery technology, principles and reconstruction. Manuals on Archaeology Series, $N^{\circ} 4$. Taraxacum Press. Washington DC.

Santillán de Andrés, S. y T. R. Ricci. 1980. Geografía del Tucumán (consideraciones generales). Universidad Nacional de Tucumán. San Miguel de Tucumán.

Sayago, J. M., J. A. Zinck, M. M. Collantes y M. Toledo. 2003. Evolución ambiental de los Valles Preandinos y la Llanura Chaqueña Occidental Argentina durante el Pleistoceno Tardío y el Holoceno. /l Congreso Argentino de Cuaternario y Geomorfología. San Miguel de Tucumán.

Scattolin, M. C. 2007. Santa María antes del año mil. Fechas y materiales para una historia cultural. V. I. Williams, B. N. Ventura, A. B. M. Callegari y H. D. Yacobaccio Editores, Sociedades Precolombinas Surandinas. Temporalidad, Interacción y Dinámica Cultural del NOA en el Ambito de 
los Andes Centro-Sur, pp. 203-219, Universidad Nacional de Buenos Aires, Buenos Aires.

Scattolin, M. C., M. F. Bugliani, L. I. Cortés, M. Calo, L. Pereyra Domingorena y A. D. Izeta. 2009. Pequeños mundos: hábitat, maneras de hacer y afinidades en aldeas del valle del Cajón, Catamarca. Relaciones de la Sociedad Argentina de Antropología, XXXIV: 251-274. http://www.saantropologia.com.ar//wpcontent/uploads/2015/01/Relaciones\%2034/11\%20 Scatolin\%20final.pdf (Última consulta: 25/08/2016).

Schiffer, M. B. 1996. Formation processes of the archeological record. University of Utah Press. Salt Lake City.

Sesma, P. J., E. Y. Guido y M. E. Puchulu. 2010. Geología de la ladera oriental de la sierra de San Javier, soporte físico para la gestión territorial. H. R. Grau Editor, Ecología de una Interfase Natural y Urbana. La sierra de San Javier y el Gran San Miguel de Tucumán, Capítulo 2 pp. 19-32, Universidad Nacional de Tucumán (EDUNT), San Miguel de Tucumán.

Schlanger, S. 1992. Recognizing persistent places in Anasazi settlement system. Space. J, Rossignol y L. Wandsnider Editores, Time, and Archaeological Landscapes, pp. 91-112. Plenum Press, New York.

Stein, J. K. 1983. Earthworm activity: a source of potential disturbance of archaeological sediments. American Antiquity, 48 (2): 277-289.

Tani, M. 1995. Beyond the identification of formation processes: behavioral inference based on traces left by cultural formation processes. Journal of Archaeological Method and Theory, 2 (3): 231-252. 